This article was published in Advanced Energy Materials, 5(24), 2015

http://dx.doi.org/10.1002/aenm.201501537

\title{
Transparent Cuprous Oxide Photocathode Enabling a Stacked Tandem Cell for Unbiased Water Splitting
}

Paula Dias, Marcel Schreier, S. David Tilley, Jingshan Luo, João Azevedo, Luísa Andrade, Dongqin Bi, Anders Hagfeldt, Adélio Mendes, Michael Grätzel, and Matthew T.Mayer*

P. Dias, J. Azevedo, Dr. L. Andrade, Prof. A. Mendes Laboratório de Engenharia de Processos Ambiente, Biotecnologia e Energia Faculdade de Engenharia da Universidade do Porto Rua Dr. Roberto Frias, 4200-465 Porto, Portugal

M. Schreier, Dr. J. Luo, Dr. D. Bi, Prof. A. Hagfeldt, Prof. M. Grätzel, Dr. M. T. Mayer Laboratory of Photonics and Interfaces Institut des Sciences et Ingénierie Chimiques École Polytechnique Fédérale de Lausanne Station 6, 1015 Lausanne, Switzerland

E-mail: matthew.mayer@epfl.ch

Prof. S. D. Tilley Department of Chemistry University of Zurich

8057 Zurich, Switzerland

Photoelectrochemical water splitting represents an attractive method of capturing and storing the immense energy of sunlight in the form of hydrogen, a clean chemical fuel. Given the large energetic demand of water electrolysis, and the defined spectrum of photons available from incident sunlight, a two absorber tandem device is required to achieve high efficiencies. The two absorbers should be of different and complementary bandgaps, connected in series to achieve the necessary voltage, and arranged in an optical stack configuration to maximize the utilization of sunlight. This latter requirement demands a top device that is responsive to high-energy photons but also transparent to lower-energy photons, which pass through to illuminate the bottom absorber. Here, cuprous oxide ( $\mathrm{Cu}_{2} \mathrm{O}$ ) is employed as a top absorber component, and the factors influencing the balance between transparency and efficiency toward operation in a tandem configuration are studied. Photocathodes based on $\mathrm{Cu}_{2} \mathrm{O}$ electrodeposited onto conducting glass substrates treated with thin, discontinuous layers of gold achieve reasonable sub-bandgap transmittance while retaining performances comparable to their opaque counterparts. This new high-performance transparent photo- cathode is demonstrated in tandem with a hybrid perovskite photovoltaic cell, resulting in a full device capable of standalone sunlight-driven water splitting.

\section{Introduction}

Sunlight is the largest and most widespread source of renewable energy, but although the market for photovoltaics is growing by around $40 \%$ per year, ${ }^{[1]}$ the intermittent and diurnal nature of solar power requires the development of an efficient method of energy storage to accommodate the global energy demand. The use of sunlight toward the direct production 
of chemical fuels is a promising route and, in particular, hydrogen generated via photoelectrochemical (PEC) water splitting represents a clean and energy-dense fuel.[2] With the aim of achieving energy conversion on a simple single device, PEC water splitting cells integrate the processes of sunlight collection and water electrolysis to produce hydrogen and oxygen, gaseous molecules which can recombine in fuel cells to efficiently utilize their stored energy.

Under standard conditions, the electrolysis of water has a reversible cell voltage of $1.23 \mathrm{~V}$, but due to reaction overpotentials a voltage of $1.5 \mathrm{~V}$ or greater is required to drive water splitting at meaningful rates. Accomplishing this with a single material photoelectrode would require discovery of a semiconductor with demanding energetic requirements, since its conduction and valence bands must properly straddle the water redox potentials plus overpotentials.[2] No ideal single material has been discovered that can drive this reaction with reasonable efficiency, although high-throughput searches are underway.[3] A more promising approach is to employ a two- absorber tandem comprising a wider bandgap transparent top absorber stacked above a smaller bandgap component. [4] By detailed balance calculations, the ideal pair of bandgaps would be approximately $1.7 \mathrm{eV}$ (absorbing wavelengths up to $730 \mathrm{~nm}$ ) and $1.1 \mathrm{eV}$ (up to $1127 \mathrm{~nm}$ ).[5] The theoretical maximum water splitting efficiency for such a system exceeds that of a single- absorber system, a result of the more complete solar spectral utilization and the ability to produce additive photovoltages toward the electrolysis demand.

Dual-absorber tandem devices can be accomplished with photoanode-photocathode systems (PEC-PEC) or photoelectrode-photovoltaic coupled devices (PEC-PV) to generate the sufficient driving force for standalone solar water splitting while simultaneously maximizing the fraction of solar energy collected. Among the various studied tandem configurations, the benchmark performances were achieved by devices using efficient III-V materials. [6] Since the balance between materials availability, fabrication cost and device performance must be optimized to realize a competitive device, most recent attention has targeted the discovery and development of Earth-abundant materials for use toward these goals. A tandem cell combining an Earth-abundant solar cell with an oxide-based photoelectrode could be an ideal solution to obtain cost-effective unassisted water splitting.[4]

Studies employing the PEC-PV configuration have mostly focused around the use of $\mathrm{n}$ type semiconductor photoanodes for water oxidation as the PEC component, largely due to the number of promising candidate materials in this class, their suitable bandgaps and their Earth-abundant nature. Among them, $\mathrm{Fe}_{2} \mathrm{O}_{3},{ }^{[7]} \mathrm{BiVO}_{4},{ }^{[8]}$ and WO [7a,9] have been employed most commonly in approaches succeeding at unassisted water splitting. Comparatively fewer Earth-abundant candidates exist for photocathode PEC devices, with even fewer demonstrated toward complete water splitting in tandem systems. [10] While photocathode stability can prove to be a challenge, Seger et al. have recently suggested that when effective surface passivation strategies are used, tandems based on photocathodes as the larger bandgap component may offer several advantages over photoanode-based approaches.[11]

To this end, p-type photocathode materials for water reduction are a topic of ongoing research.[12] Copper-oxide-based materials, such as cuprous oxide $\left(\mathrm{Cu}_{2} \mathrm{O}\right)$, have gained significant interest due to their elemental abundance, scalable synthesis techniques, and natural p-type character.[13] Moreover, the $\mathrm{Cu}_{2} \mathrm{O}$ bandgap energy around $2.1 \mathrm{eV}$, and its appropriate 
band edge positions, make it appealing for solar hydrogen production from water, although its poor stability in aqueous solutions is a limiting factor for its use. Paracchino et al. developed a highly active and stable multilayer composite photocathode that consists of a $\mathrm{p}-\mathrm{n}$ junction between electrodeposited p-type $\mathrm{Cu}_{2} \mathrm{O}$ and n-type overlayers of $\mathrm{Al}$-doped zinc oxide (AZO) and $\mathrm{TiO}_{2} \cdot{ }^{[14]}$

The device was recently demonstrated as part of a PEC- PEC tandem capable of complete water splitting at modest efficiency. [10a]

Despite the recent success with this device architecture, the photovoltage produced by this photocathode alone is insuffi- cient to drive complete water splitting, so it should ideally be incorporated as the top, wide-bandgap component of a tandem system. However, the fact that the $\mathrm{Cu}_{2} \mathrm{O}$ thin films are typically electrodeposited onto an opaque Au layer precludes their use as a top absorber. Therefore the development of an efficient

and stable transparent $\mathrm{Cu}_{2} \mathrm{O}$ thin film device is an important goal, wherein the portion of solar radiation not absorbed by the photocathode can be transmitted and utilized by a second photoabsorber. In this work, an innovative tandem device was enabled by the development of a transparent $\mathrm{Cu}_{2} \mathrm{O}$ photo- cathode, which when connected in series with a hybrid per- ovskite photovoltaic was demonstrated to perform unassisted sunlight-driven water splitting.

\section{Results and Discussion}

2.1. Transparent Au Substrates for $\mathrm{Cu} 2 \mathrm{O}$ Photocathodes

The photocathode device structure employed herein is depicted in Figure 1. Electrodeposited p-type $\mathrm{Cu}_{2} \mathrm{O}$ serves as the light absorbing component, producing photogenerated electrons for water reduction. As previously demonstrated, atomic layer deposition (ALD) overlayers of $\mathrm{Al}: \mathrm{ZnO}(\mathrm{AZO})$ and $\mathrm{TiO}_{2}$ enable heterojunction formation and corrosion protection, respectively, $[14 \mathrm{~b}]$ and electrodeposited $\mathrm{RuO}_{2}$ represents a highly active and stable catalyst for the hydrogen evolution reaction.[15] In this study, these three overlayers remained unchanged while the substrate and absorber characteristics were varied. In the majority of previous works employing $\mathrm{Cu}_{2} \mathrm{O}$ as photoabsorber in PV and PEC devices, a thick and opaque gold film was used as the hole- collecting contact to $\mathrm{Cu}_{2} \mathrm{O} .[12 \mathrm{~d}, 13,16]$ This arrangement prevents implementation of such devices in an optical tandem, since the longwavelength portion of the solar spectrum cannot pass through to the second absorber. Our first task was therefore to adapt the substrate to enable light transmittance. Films of the transparent conducting oxide $\mathrm{SnO}_{2}: \mathrm{F}$ (FTO) on glass are routinely used as substrate for transparent electronic devices, so we began by attempting the photocathode synthesis using Au-free, pristine FTO glass as substrate. As shown in Figure 2, the cur- rent densitypotential $(J-E)$ response of the device formed on bare FTO was considerably poorer than that of a typical device grown on a continuous $150 \mathrm{~nm}$ thick Au film. For a photo- cathode driving water reduction, the goal is to achieve large photocurrents at potentials well positive of the reversible potential of hydrogen evolution, $0 \mathrm{~V}$ vs. RHE (reversible hydrogen electrode). The typical device based on thick Au exhibits a photocurrent (Jph) onset potential of approximately $+0.5 \mathrm{~V}$ vs. RHE, and reaches cathodic $J_{\mathrm{ph}}$ approaching $-6 \mathrm{~mA}$ 
$\mathrm{cm}^{-2}$ at $0 \mathrm{~V}$ vs. RHE, a performance that is among the best for photoelectrodes based on metal oxide semiconductors. However, the PEC response suffered significantly in the absence of $\mathrm{Au}$, with a very gradual onset and a $J_{\mathrm{ph}}$ reaching only $-2 \mathrm{~mA} \mathrm{~cm}{ }^{-2}$ at $0 \mathrm{~V}$ vs. RHE. This transparent, Au-free device ultimately reached significant photocurrents, but only at large overpotential for water reduction.

This behavior suggests that a significant resistive element is present in this device configuration. A key role of the substrate contact to $\mathrm{Cu}_{2} \mathrm{O}$ is to form an ohmic junction for photogenerated hole collection. [13,17] Due to the relatively large work function of p-type $\mathrm{Cu}_{2} \mathrm{O}$, this constrains the contact material to one with a comparable or larger work function. It is likely that the $\mathrm{Cu}_{2} \mathrm{O}$ contact with FTO is not an ideal ohmic junction, but rather forms a slight Schottky barrier opposing the collection of holes, and therefore contributes to the worsening of the $J-E$ response. Indeed, electrochemical impedance spectroscopy analysis revealed a resistive element for this bare FTO device, a feature that was nonexistent in devices with $\mathrm{Au}$ at the interface with $\mathrm{Cu}_{2} \mathrm{O}$ (Figure S1, Supporting Information). Additionally, the electrodeposited $\mathrm{Cu}_{2} \mathrm{O}$ exhibited quite different morphology when grown on bare FTO, proceeding by the nucleation and growth of large and dispersed $\mathrm{Cu}_{2} \mathrm{O}$ crystals, in contrast to the dense, uniform and continuous growth of $\mathrm{Cu}_{2} \mathrm{O}$ films when using a gold-coated substrate. This behavior is depicted in Figure 3 via electron microscopy images of the different substrates before and after device fabrication, and correlates with previous reports on the substrate dependence of $\mathrm{Cu}_{2} \mathrm{O}$ electrodeposition.[18] Therefore, the $\mathrm{Au}$ substrate seems to affect both the electronics of the junction and the quality of the electrodeposited films, making its presence important for the device performance but a challenge given our goal of trans- parent devices.

We hypothesized that very thin layers of Au could be used to overcome these limitations while also allowing a high degree of transparency, and therefore explored the effect of using substrates of FTO treated by brief sputter depositions of Au. As shown in Figure 3c, sputtering Au for an equivalent dose (based on calibrated film deposition rates) of $3 \mathrm{~nm}$ led to the formation of a discontinuous island coating on the FTO sur- face. Note that the Au substrates are herein labeled by their nominal thickness based on calibrated sputter deposition rates, although this does not accurately define the discontinuous morphology. Interestingly, $\mathrm{Cu}_{2} \mathrm{O}$ electrodeposition onto these $\mathrm{Au}$ island substrates resulted in dense, uniform, and crystalline films (Figure 3f), similar to those deposited onto thick Au and in contrast to the large $\mathrm{Cu}_{2} \mathrm{O}$ particles which form on bare FTO substrates. Examination of the transmittance of Au-coated FTO glass (Figure 4a) revealed that these substrates exhibit reason- able transparency across the spectrum, but the transparency drops with increasing amounts of gold.

Employing these as substrates for the fabrication of $\mathrm{Cu}_{2} \mathrm{O}$ photocathodes, we discovered that the devices were indeed capable of efficient operation. In Figure $4 b$, the PEC response for devices based on the three different Au-treated substrates reveals that even a small amount of gold can enable photo- cathodes with onset potentials and $J_{\mathrm{ph}}$ values comparable to that obtained on thick Au. The performance is dependent on the amount of Au used, as the shape of the $J-E$ curve improves with increased Au. For the smallest dose of $1 \mathrm{~nm} \mathrm{Au}$, the slow, rather linear increase in $J_{\mathrm{ph}}$ is likely due to a series resistance effect resulting from the limited interfacial area between $\mathrm{Au}$ and $\mathrm{Cu}_{2} \mathrm{O}$. With increased $\mathrm{Au}$, the apparent fill factor of 
the curves improves, but the transparency begins to suffer as a result of the coalescence of $\mathrm{Au}$ particles and the formation of continuous films. Note that the photocurrent transient behavior near the photocurrent onset, similar across all devices studied here, seems to result from the capacitive charging of the $\mathrm{TiO}_{2}$ overlayer or the $\mathrm{RuO}_{2}$ catalyst; these observations are presently under study. We have therefore established FTO-glass substrates with slight $\mathrm{Au}$ treatments as suitable substrates for enabling transparent $\mathrm{Cu}_{2} \mathrm{O}$-based devices, while identifying that the balance between transmittance and performance will be important in optimizing the tandem device. In this regard, we selected the $3 \mathrm{~nm}$ dose of sputtered Au as substrate for the studies continued below.

\subsection{Effects of $\mathrm{Cu}_{2} \mathrm{O}$ Absorber Thickness}

The next parameter to consider is the $\mathrm{Cu} 2 \mathrm{O}$ absorber layer thickness. Our previous reports employed $\mathrm{Cu}_{2} \mathrm{O}$ films of $500 \mathrm{~nm}$ or greater, while other groups have used thicknesses of several micrometers for photovoltaics based on electrodeposited $\mathrm{Cu}_{2} \mathrm{O} .[16]$ Meanwhile, the device transparency and the application of $\mathrm{Cu}_{2} \mathrm{O}$ in dual-absorber tandems have been little explored.[19] In this work, transparency was an important factor, and we therefore examined a series of $\mathrm{Cu}_{2} \mathrm{O}$ thicknesses by varying the duration of electrodeposition onto substrates of FTO treated with $3 \mathrm{~nm}$ doses of Au. Three durations were explored, with 105, 50, and $25 \mathrm{~min}$ electrodepositions producing film thicknesses of approximately 500, 260, and $100 \mathrm{~nm}$, respectively (see Figure S2, Supporting Information, for electron images and photographs of the films). As shown in Figure 4c, the devices exhibited varying photocathode performances. The device with the thinnest absorber layer $(100 \mathrm{~nm})$ showed diminished plateau photocurrents, whereas the 260 and $500 \mathrm{~nm}$ films exhibited nearly identical $J-E$ responses, both being comparable to the performance on a typical thick $\mathrm{Au}$ substrate. Variation in the absorber thickness modifies the light absorption profile and the resulting quantum efficiency spectra. In Figure $4 \mathrm{~d}$, the incident photon-to-current conversion efficiencies (IPCE) of the devices under monochromatic illumination reveal the changes in spectral response. Although the bandgap of $\mathrm{Cu}_{2} \mathrm{O}$ is often stated as being approximately $2.1 \mathrm{eV}$, the nature of this transition is direct but forbidden, whereas the first allowed transition occurs at around $2.5 \mathrm{eV} .[13,20]$ This effect is clearly seen as an inflection in the IPCE spectra, where photons of lower energy (wavelengths longer than $500 \mathrm{~nm}$ ) are poorly utilized by these thin $\mathrm{Cu}_{2} \mathrm{O}$ films. Film thicknesses of several micrometers are required for significant absorption in this range, $[19 \mathrm{a}]$ but for a stacked tandem device the transmittance of long-wavelength photons is an important factor, and it can be seen that even a $500 \mathrm{~nm} \mathrm{Cu} 2 \mathrm{O}$ film contributes to significantly decreased transmittance as compared to a $260 \mathrm{~nm} \mathrm{Cu} 2 \mathrm{O}$ device (Figure 4d). This loss is possibly due to an increase in scattering or reflection due to the visibly larger degree of surface roughness for the thick $\mathrm{Cu}_{2} \mathrm{O}$ films (Figure S2a, Supporting Information). Furthermore, the response to short wavelengths decreases with thicker absorber layers, a result of the poor majority carrier (hole) collection in thick films. The 50 min electrodeposition photocathode was therefore selected as a relatively optimized candidate for balancing PEC performance with optical transparency in the complete water splitting device. 


\subsection{Tandem Device for Complete Water Splitting}

A schematic of the assembled tandem device is shown in Figure 5, where the two absorbers are placed back-to-back, the photovoltaic electron collector is wired to the photocathode, and its hole collector is wired to a water oxidation anode. In a dual- absorber PEC-PV tandem, the photoelectrode and the photo- voltaic utilize photons of different regions of the solar spectrum to enable broad sunlight harvesting. Furthermore, since they will be connected in series and therefore operate at the same current density, it is desirable for their individual photocurrent responses to be well matched. In Figure 6a, the IPCE responses of the photocathode and the perovskite photovoltaic (behind the photocathode) are multiplied by the AM1.5G onesun photon flux to reveal the expected photogenerated electron flux from each device, which when integrated yields their expected photocurrent densities.

In constructing a PEC-PV tandem for complete water splitting, three components are required: a suitably transparent photocathode driving hydrogen evolution, a photovoltaic cell responsive to the transmitted photons, and an anode for oxygen evolution. Among water oxidation catalysts, $\mathrm{IrO}_{2}$ is known to be a top performer, [21] and was therefore our anode choice for this proof-of-concept device. Even so, the water oxidation reaction imparts a large energetic demand on the overall water splitting processes, especially in near-neutral solutions, and significant overpotentials beyond the reversible potential for oxygen evolution (1.23 V vs RHE) are required to achieve meaningful current densities. In the tandem configuration employed here, the flat anode electrode is positioned parallel to the path of light, an approach that allows scaling its active area beyond that of the illuminated area as a tactic toward reducing the overpotential required for supporting the tandem photocurrent. In previous reports of PECPV tandems for unbiased water splitting, it has been common to either make no mention of the counter electrode dimensions or to employ counter electrode areas that are several times larger than the photoelectrode illuminated area. $[7 \mathrm{a}, 8 \mathrm{~b}, 22]$ This non-trivial parameter plays an important role in the tandem construction and performance, and here we used a catalyst with an active area of approximately 30 times that of the photocathode illuminated area. While the anode overpotential is a key challenge producing an efficient tandem device, this mismatch of electrode areas can actually highlight an advantage of a photocathode-based tandem. Since the oxygen evolution reaction, which exhibits significantly larger overpotentials than the hydrogen evolution reaction, occurs on a non-photoactive component, its relative area may be increased as long as the cell design allows its placement out of the path of illumination, an approach that is even more desirable when abundant catalyst materials are employed.

Figure $6 \mathrm{~b}$ presents the $J-E$ behavior of all three components tested individually, where the raw current of each was normalized by the photocathode illuminated area. Comparison of the photocathode and anode curves reveals the current-dependent additional voltage needed to enable complete electrolysis. For instance, around $1 \mathrm{~V}$ is needed in order to drive a current density of $2 \mathrm{~mA} \mathrm{~cm}^{-2}$ between these electrodes. Few single-absorber photovoltaics are capable of photovoltages this large, but the emergent high- $V_{\mathrm{OC}}$ hybrid perovskite photovoltaics rep- resent promising candidates for this application. [23] Here, we employed a PV cell based on the mixed-cation formulation form- amidinium methylammonium lead iodide $\left((\mathrm{MA}) x(\mathrm{FA}) 1-x \mathrm{PbI}_{3}{ }^{[24]}\right.$ that exhibits a $V_{\mathrm{Oc}}$ under one sun illumination of $1.13 \mathrm{~V}$ (see Figure $\mathrm{S} 3$, Supporting Information, for the photovoltaic cell $J-V$ and IPCE analysis). The PV cell was placed against the back window of the sealed PEC cell and connected by wires to the 
electrodes. Since the PV is electrically in series between the anode and photocathode, its $J-V$ response can be plotted between the electrode $J-E$ curves in order to predict the tandem operation current. Under operation, the currents through each component are equal, and the potentials of each contact spontaneously adjust to reach this equilibrium. As shown in Figure $6 \mathrm{~b}$, this treatment predicts an operating current density of about $2 \mathrm{~mA} \mathrm{~cm}^{-2}$ for this tandem configuration. We then connected all components in series and illuminated the cell with one-sun intensity simulated sunlight, using a potentiostat to monitor the current flowing between the PV and anode (applying zero bias) while simultaneously performing inline gas chromatography measurement of the evolved gases. Figure $6 c$ shows the resulting measured current density, where it can be seen that the actual tandem performance corresponded well with that predicted by the separate component analysis. Measurement of both hydrogen and oxygen, important for proving complete water splitting, [25] led to calculated Faradaic efficiencies around 100\% for each gas (Figure 6d). Variations in the gas measurements are a result of the buildup and release of bubbles on the electrode surfaces.

A $J_{\mathrm{ph}}$ of $2 \mathrm{~mA} \mathrm{~cm}{ }^{-2}$ combined with the near-unity yield of evolved gases corresponds to a solar-to- hydrogen (STH) efficiency of $2.5 \%$ by Equation (1):

$$
\mathrm{STH}=\frac{J_{\mathrm{ph}}\left(\mathrm{mAcm}^{-2}\right) \times 1.23 \mathrm{~V} \times \eta_{\mathrm{F}}}{P_{\text {in }}\left(\mathrm{mWcm}^{-2}\right)}
$$

where $J_{\mathrm{ph}}$ is the photocurrent density during unbiased operation, $1.23 \mathrm{~V}$ is the standardstate potential for water electrolysis, $\eta_{\mathrm{F}}$ is the Faradaic efficiency of evolved hydrogen, and $P_{\text {in }}$ is the power of the incident illumination, taken here as $100 \mathrm{~mW} \mathrm{~cm}-2$ for the AM1.5G spectrum at one sun intensity. This efficiency, while modest in comparison to more sophisticated systems, [6] represents an important advance among photocathode-based tandem devices employing Earth- abundant absorbers.

The tandem device was tested under continuous illumination for over $2 \mathrm{~h}$, during which time the $J_{\mathrm{ph}}$ slowly decreased to stabilize at around $1.5 \mathrm{~mA} \mathrm{~cm}-2$. In addition to measurements of $J_{\mathrm{ph}}$ and $\eta \mathrm{F}$, monitoring the device potentials during operation revealed insight into the tandem operation. By periodically measuring the electrode potentials against a reference electrode in the cell as illustrated in Figure 5 and shown in Figure 6e, we observed that the anode potential was quite stable whereas the photocathode potential shifted to more positive values over time. These changes were concurrent with the gradual decrease of device $J_{\mathrm{ph}}$, and the behavior can be interpreted by referring to the analysis in Figure 6b. The measured potentials represent the potentials at the contacts between the PV cell and each electrode, equivalent to the labeled crossover points. Since the anode curve is steep, changes in current are accommodated with relatively little change in potential. For the photocathode, on the other hand, the observed positive shift in potential, combined with the decreasing measured $J_{\mathrm{ph}}$, reveals that the performance decline is likely a result of a decrease in the PV photovoltage. Indeed, when its $J-V$ response was re-tested after tandem operation, the PV cell $V_{\mathrm{OC}}$ and fill-factor exhibited a slight decrease (Figure S3, Supporting Information). Despite this observation, we note that several recent works have demonstrated extended stability 
for hybrid perovskite photovoltaics, [26] and this is a topic of ongoing study for the device type employed here. Meanwhile, the photocathode was found to be robust. In an extended test, a representative $\mathrm{Cu}_{2} \mathrm{O}$ photocathode of this same transparent configuration was found to be highly stable when tested for $24 \mathrm{~h}$ under continuous operation (Figure S4, Supporting Information).

There are several clear paths toward improving upon this tandem efficiency, mostly based on the enhancement of the $\mathrm{Cu}_{2} \mathrm{O}$ photocathode performance. As shown above, the $J_{\mathrm{ph}}$ is highly dependent on the operating potential. An increase in the photovoltage of the device, manifesting as a positive shift in the $J-E$ curve, would allow tandem operation at higher current density. For instance, a photovoltage increase of $0.2 \mathrm{~V}$ could enable a near-doubling of the operating current density to $\approx 4 \mathrm{~mA} \mathrm{~cm}^{-2}$. Recently it has been shown that improving the nature of the $\mathrm{Cu}_{2} \mathrm{O}$-overlayer junction by using $\mathrm{Ga}_{2} \mathrm{O}_{3}$ interlayers can lead to significantly enhanced photovoltages, $[16 \mathrm{~b}, 27]$ an approach that may prove useful toward tandem applications. Improvement in the photocathode photocurrent is also needed, although the forbidden electronic transitions for photon energies below $2.5 \mathrm{eV}$ require much thicker $\mathrm{Cu} O$ films for improved absorption in that range, ${ }^{20]}$ posing a challenge when targeting high device transparency.

The tandem performance may also be improved by operating in a highly alkaline or acidic electrolyte more suitable for efficient electrolysis. Although rapid stirring was used here to prevent mass transport limitations and $\mathrm{pH}$ gradient build-up, it has been shown that devices in near-neutral solutions can be fundamentally limited in efficiency when operated for extended periods. [28] Furthermore, catalysts for water oxidation are generally more efficient in alkaline solutions, for which there are several desirable Earth-abundant candidates. [21] At present, we found this $\mathrm{TiO}_{2}$ overlayer approach to be insufficiently stable in alkaline conditions to allow a demonstration extended operation, but further study in this direction is ongoing, [29] since a stable and efficient photocathode in alkaline solution would be highly desirable.

\section{Conclusion}

In this work, we constructed a PEC-PV water splitting tandem using a $\mathrm{Cu}_{2} \mathrm{O}$ photocathode and a hybrid perovskite photovoltaic. In developing a transparent photocathode, we discovered the important role of gold as substrate and explored how different aspects of the device architecture influence the balance between performance and transparency. This transparent photoelectrode enabled the construction of an optically stacked two absorber tandem device capable of performing standalone sunlight-driven water splitting at up to $2.5 \%$ solar-to-hydrogen efficiency, a performance that may be significantly enhanced by further development of the $\mathrm{Cu}_{2} \mathrm{O}$ photocathode.

\section{Experimental Section}

Cu2O Photocathode Preparation: The films of cuprous oxide were electrodeposited onto fluorine-doped tin oxide (FTO, TEC-15, NSG glass) substrates with or without Au treatments. The FTO-glass substrates were cleaned by sequential ultrasonic treatments in soapy water (15 min), acetone (15 min), ethanol (15 min), and deionized water (15 $\min )$. The substrates were then coated with various treatments of Au by DC sputtering. The 
standard opaque films of $150 \mathrm{~nm}$ were deposited at a calibrated rate of $1.1 \mathrm{~nm} \mathrm{~s}^{-1}$ (after depositing a $10 \mathrm{~nm}$ Cr adhesion layer). The transparent Au treatments (without Cr layers) were performed at a calibrated rate of $0.2 \mathrm{~nm} \mathrm{~s}^{-1}$ for durations 5,15 , and $25 \mathrm{~s}$ to yield the substrates labeled herein by their nominal thicknesses of 1,3 , and $5 \mathrm{~nm} \mathrm{Au}$. The electrodeposition of cuprous oxide from a basic solution of lactate-stabilized copper sulfate was performed as described previously.[30] The electrodeposition was performed in galvanostat mode (constant current density of $-0.1 \mathrm{~mA} \mathrm{~cm}-2$ ) by using a two-electrode configuration with a platinum mesh as the counter electrode. The time of deposition was varied as described in the main text. Thin n-type oxide overlayers were deposited atop the Cu2O films by ALD using a thermal ALD system (Savannah 100, Cambridge Nanotech), as described previously.[15] The ALD protective structure consisted of $20 \mathrm{~nm}$ of Al:ZnO (AZO; deposited at $120^{\circ} \mathrm{C}$ using precursors of diethyl zinc, trimethylaluminum, and water vapor) followed by $100 \mathrm{~nm}$ of $\mathrm{TiO} 2$ (deposited at $150{ }^{\circ} \mathrm{C}$ using precursors of tetrakis(dimethylamino) titanium at $75^{\circ} \mathrm{C}$ and $\mathrm{H}_{2} \mathrm{O} 250 \%$ in water). After ALD, the electrode areas were defined by encapsulation using hot glue or opaque epoxy. Onto the exposed active area, $\mathrm{RuO} 2$ catalyst was galvanostatically deposited under illumination using an aqueous solution of $1.3 \times 10^{-3} \mathrm{M}$ KRuO4. The deposition was carried out at a current density of $-28.3 \mu \mathrm{Acm}^{-2}$ for $15-20$ min under simulated one sun illumination, following the procedure described previously.[15]

Spectroscopic and Microscopic Characterization: The morphology of the substrates and photoelectrodes was characterized using a high- resolution scanning electron microscope (Zeiss Merlin) with an in-lens secondary electron detector. Cross-sectional images were acquired from freshly cleaved surfaces. Total transmittance spectra were measured with a spectrophotometer (Shimadzu UV-3600) equipped with an integrating sphere. The partial devices were tested directly in air, whereas the full devices were wetted with water and sandwiched between quartz slides in order to approximate the optical behavior of the device within the PEC cell. The absence of sample was used as a transmittance blank in order to account for the contribution of every layer in the device.

Electrochemical Characterization: The PEC cell performance was evaluated in a standard three-electrode configuration using the $\mathrm{Cu} 2 \mathrm{O}$ device as photocathode, a Pt wire as counter electrode, and a reference electrode of $\mathrm{Ag} / \mathrm{AgCl} / \mathrm{sat}$. $\mathrm{KCl}$. The electrolyte solution was $\mathrm{Na} 2 \mathrm{SO} 4(0.5 \mathrm{M})$ buffered with phosphate $(0.1 \mathrm{M})$ to obtain $\mathrm{pH}$ 5.0. An Ivium Potentiostat/Galvanostat was used to acquire the photoresponse under chopped irradiation from a $450 \mathrm{~W}$ Xe lamp (Osram, ozone-free) equipped with an IR/UV filter (KG3 filter, $3 \mathrm{~mm}$, Schott). The PEC cell was positioned for illumination at one-sun intensity, the position determined by measuring the short-circuit current on a calibrated silicon diode fitted with a KG3 filter to obtain low spectral mismatch with the AM 1.5 spectrum across the relevant wavelength range of $300-800 \mathrm{~nm}$. The scan rate for all current-potential (JE) studies was $10 \mathrm{mV} \mathrm{s}^{-1}$ in the cathodic direction. The electrolyte was continuously bubbled with nitrogen during the $J-E$ measurements and stability tests to remove oxygen and thus eliminate signals of oxygen reduction. 
IPCE measurements were performed under light from a $300 \mathrm{~W}$ xenon lamp (Cermax PE $300 \mathrm{BUV}$ ) passing through a monochromator (Bausch \& Lomb). In three-electrode configuration the photocathode current response was measured while holding the potential constant. This photoresponse was compared against that of a calibrated $\mathrm{Si}$ photodiode to determine the IPCE at each wavelength.

Photovoltaic Preparation: A $50 \mathrm{~nm}$ compact TiO2 blocking layer was first deposited onto the surface of a precleaned FTO substrate by spray pyrolysis on a hotplate at $450{ }^{\circ} \mathrm{C}$ using Tiisopropoxide and acetylacetone in ethanol. Then a nanostructured layer of $\mathrm{TiO}_{2}$ was deposited by spin-coating diluted Dyesol paste (18NR-T), and sintering at $500^{\circ} \mathrm{C}$ for $20 \mathrm{~min}$. The desired perovskite solutions of (FAPbI)3-x(MAPbI3) $x$, were prepared by dissolution of $\mathrm{CH}_{3} \mathrm{NH}_{3} \mathrm{Br}$, $\mathrm{NH}_{2} \mathrm{CH}_{-} \mathrm{NH}_{2} \mathrm{I}$, with $\mathrm{PbI} 2$ and $\mathrm{PbBr} 2$ in the mixed solvent of DMSO and DMF. The mixed perovskite film was obtained by spin-coating the precursor solution, followed by antisolvent treatment. The coated films were then placed on a hot plate set at $100{ }^{\circ} \mathrm{C}$ to evaporate the solvent. The composition of hole transport material was 2,2',7,7'-tetrakis( $\mathrm{N}, \mathrm{N}$-di- p-methoxyphenyl-amine)-9,99-spirobifluorene (spiro-OMeTAD, $0.06 \mathrm{M}$, Lumtec.), bis(trifluoromethane)sulfonimide lithium salt (LiTFSI, 0.030 M, 99.95\%, Aldrich), FK209 (Co[t-BuPyPz]3[PF6]3, $0.0024 \mathrm{M}$ ), and 4-tert-butylpyridine $(0.2 \mathrm{M}, 99 \%$, Aldrich) in anhydrous chlorobenzene $\left(99.8 \%\right.$, Aldrich). The perovskite-sensitized $\mathrm{TiO}_{2}$ films were coated with HTM solution using spin-coating, followed by deposition of Au (80 nm) as electrode by thermal evaporation.

IrO2 Anode Preparation: A $1.8 \mathrm{~cm}^{2}$ square piece of titanium foil $(99.7 \%, 0.25 \mathrm{~mm}$; Sigma Aldrich) was etched for $60 \mathrm{~min}$ in boiling oxalic acid (1 M, $\geq 97 \%$, anhydrous, Fluka). Subsequently, $\mathrm{H}_{2} \mathrm{IrCl} 6$ (30 $\mu \mathrm{L}, 0.2 \mathrm{M}, 99.9 \%$, hydrate, ABCR) in isopropanol (ACS Reagent, Merck) were drop cast on the foil. This was followed by drying at $70{ }^{\circ} \mathrm{C}$ for 10 min and calcination at $500{ }^{\circ} \mathrm{C}$ for $10 \mathrm{~min}$ in air. The step was repeated three times on each side of the Ti foil, resulting in the deposition of $6.3 \mathrm{mg}$ of $\mathrm{IrO} 2$ onto each side.

Tandem Assembly and Testing: After defining the active area of the transparent photocathode using opaque epoxy (Loctite Hysol 9461), the device was fixed into a custom gas-tight test cell with front and back windows of quartz, gas inlet (submerged) and outlet (headspace) tubes, and feedthroughs for the anode, cathode, and reference electrodes. The IrO2 anode was positioned to the side, approximately $1 \mathrm{~cm}$ away from the photocathode surface. The $\mathrm{pH} 5$ electrolyte solution $(15 \mathrm{~mL})$ was filled into the cell, rapid stirring was applied, and a $20 \mathrm{~mL} \mathrm{~min}^{-1}$ flow of He was continuously bubbled through the cell. Behind the electrochemical cell, against the rear quartz window, was placed the perovskite photovoltaic cell, which was illuminated by light passing through the photocathode aperture. The photovoltaic FTO contact (electron collector) was connected to the photocathode by a short wire, while its gold contact (hole collector) was connected (through a potentiostat in 2-electrode configuration with zero applied bias to measure the short- circuit current) to the $\mathrm{IrO} 2$ anode. The cell was illuminated through the front window by simulated sunlight from a $450 \mathrm{~W}$ Xe lamp (Osram, ozone-free) equipped with an AM1.5G filter (LOT-QD), calibrated with a silicon diode to one sun intensity. For in-line characterization of evolved hydrogen and oxygen, the outflow was periodically injected 
into a gas chromatograph (TRACE Ultra with PDD detector, Thermo Scientific; ValcoPLOT Molesieve $5 \AA$ fused silica column).

\section{Supporting Information}

Supporting Information is available from the Wiley Online Library or from the author.

\section{Acknowledgements}

The authors thank the European Commission for supporting this work through the following Seventh Framework Programme collaborative projects: PECDEMO (ref. $\mathrm{n}^{\circ}$ 621252), PHOCS (309223), and MESOLIGHT (247404). Additionally, M.S. thanks Siemens AG, J.L. thanks Nano-Tera (TANDEM project), M.G. thanks the Swiss Federal Office for Energy (PECHouse project), and A.H. thanks the Swiss National Science Foundation NRP70 programme (154002) for financial support. P.D. and J.A. are grateful to the Portuguese Foundation for Science and Technology (FCT) for their PhD Grants (References: SFRH/BD/81016/2011 and SFRH/BD/79207/2011, respectively). L.A. acknowledges European Research Council (Contract no: 321315) for financial support. Special thanks to Jeong-Hyeok Im and F. Javier Ramos for their efforts in photovoltaic fabrication, and to Prof. Kevin Sivula for the use of the UV-vis spectrometer.

(1) Solar Power Europe (SPE), Global Market Outlook for Solar Power 2015-2019, http://www.solarpowereurope.org(accessed: May 2015).

(2) M. G. Walter, E. L. Warren, J. R. McKone, S. W. Boettcher, Q. Mi, E. A. Santori, N. S. Lewis, Chem. Rev. 2010, II0, 6446.

(3) I. E. Castelli, F. Hüser, M. Pandey, H. Li, K. S. Thygesen, B. Seger, Jain, K. A. Persson, G. Ceder, K. W. Jacobsen, Adv. Energy Mater. 2015, 5, 1400915; b) K. Sliozberg, D. Schäfer, T. Erichsen, R. Meyer, C. Khare, A. Ludwig, W. Schuhmann, ChemSusChem 2015, 8, 1270; C. Xiang, J. Haber, M. Marcin, S. Mitrovic, J. Jin, J. M. Gregoire, ACS Comb. Sci. 2014, 16, 120.

(4) M. S. Prévot, K. Sivula, J. Phys. Chem. C 2013, I I 7, 17879.

(5) S. Hu, C. Xiang, S. Haussener, A. D. Berger, N. S. Lewis, Energy Environ. Sci. 2013, 6, 2984.

(6) J. W. AgerIII, M. Shaner, K. Walczak, I. D. Sharp, S. Ardo, Energy Environ. Sci. 2015, 8, 2811; b) S. Licht, B. Wang, S. Mukerji, T. Soga, M. Umeno, H. Tributsch, J. Phys. Chem. B 2000, 104, 8920; O. Khaselev, A. Bansal, J. A. Turner, Int. J. Hydrogen Energy 2001, $26,127$.

(7) J. Brillet, J. H. Yum, M. Cornuz, T. Hisatomi, R. Solarska, J. Augustynski, M. Grätzel, K. Sivula, Nat. Photonics 2012, 6, 823; b) Gurudayal, D. Sabba, H. K. Mulmudi, L. H. Wong, J. Barber, M. Grätzel, N. Mathews, Nano Lett. 2015, 15, 3833; C. G. MoralesGuio, M. T. Mayer, A. Yella, S. D. Tilley, M. Grätzel, X. Hu, J. Am. Chem. Soc. 2015, 137, 
9927; d) J.-W. Jang, C. Du, Y. Ye, Y. Lin, X. Yao, J. Thorne, E. Liu, G. McMahon, J. Zhu, A. Javey, J. Guo, D. Wang, Nat. Commun. 2015, 6, 7447.

(8) X. Shi, K. Zhang, K. Shin, M. Ma, J. Kwon, I. T. Choi, J. K. Kim, H. K. Kim, D. H. Wang, J. H. Park, Nano Energy 2015, 13, 182; Y.-S. Chen, J. S. Manser, P. V. Kamat, J. Am. Chem. Soc. 2015, 137, 974; c) C. Ding, W. Qin, N. Wang, G. Liu, Z. Wang, P. Yan, J. Shi, C. Li, Phys. Chem. Chem. Phys. 2014, 16, 15608; d) L. Han, F. F. Abdi, R. van de Krol, R. Liu, Z. Huang, H. J. Lewerenz, B. Dam, M. Zeman, A. H. Smets, ChemSusChem 2014, 7, 2832.

(9) M. R. Shaner, K. T. Fountaine, S. Ardo, R. H. Coridan, H. A. Atwater, N. S. Lewis, Energy Environ. Sci. 2014, 7, 779; K. Walczak, Y. Chen, C. Karp, J. W. Beeman, M. Shaner, J. Spurgeon, I. D. Sharp, X. Amashukeli, W. West, J. Jin, N. S. Lewis, C. Xiang, ChemSusChem 2015, 8, 544.

(10) P. Bornoz, F. F. Abdi, S. D. Tilley, B. Dam, R. van de Krol, M. Grätzel, K. Sivula, J. Phys. Chem. C 2014, II8, 16959; b) C. Liu, J. Tang, H. M. Chen, B. Liu, P. Yang, Nano Lett. 2013, 13, 2989; C.-Y. Lin, Y.-H. Lai, D. Mersch, E. Reisner, Chem. Sci. 2012, 3, 3482.

(11) B. Seger, I. E. Castelli, P. C. K. Vesborg, K. W. Jacobsen, O. Hansen, I. Chorkendorff, Energy Environ. Sci. 2014, 7, 2397.

(12) a) J. G. Rowley, T. D. Do , D. A. Cleary , B. A. Parkinson, ACS Appl. Mater. Interfaces 2014 , 6 , 9046 ; b) C. G. Read , Y. Park , K.-S. Choi , J. Phys. Chem. Lett. 2012 , 3 , 1872 ; c) J. Gu, Y. Yan, J. W. Krizan, Q. D. Gibson, Z. M. Detweiler, R. J. Cava, A. B. Bocarsly, J. Am. Chem. Soc. 2014 , 136 , 830 ; d) P. Dai , W. Li , J. Xie, Y. He , J. Thorne, G. McMahon, J. Zhan , D. Wang, Angew. Chem. Int. Ed. 2014, 53, 13493.

(13) B. K. Meyer, A. Polity, D. Reppin, M. Becker, P. Hering, P. J. Klar, T. Sander, C. Reindl , J. Benz, M. Eickhoff, C. Heiliger, M. Heinemann, J. Bläsing, A. Krost, S. Shokovets , C. Müller , C. Ronning, Phys. Status Solidi B 2012 , 249 , 1487.

(14) a) A. Paracchino, V. Laporte, K. Sivula , M. Grätzel , E. Thimsen, Nat. Mater. 2011, 10 , 456 ; b) A. Paracchino , N. Mathews, T. Hisatomi , M. Stefi k, S. D. Tilley, M. Grätzel, Energy Environ. Sci. $2012,5,8673$.

(15) S. D. Tilley, M. Schreier, J. Azevedo, M. Stefi k, M. Grätzel , Adv. Funct. Mater. 2014 $, 24,303$.

(16) a) C. M. McShane, K.-S. Choi , Phys. Chem. Chem. Phys. 2012 , 14 , 6112 ; b) Y. S. Lee, D. Chua , R. E. Brandt, S. C. Siah , J. V. Li , J. P. Mailoa , S. W. Lee , R. G. Gordon, T. Buonassisi , Adv. Mater. 2014, $26,4704$.

(17) A. E. Rakhshani, Solid-State Electron. $1986,29,7$.

(18) Y. L. Liu , Y. C. Liu , R. Mu, H. Yang, C. L. Shao, J. Y. Zhang, Y. M. Lu , D. Z. Shen, X. W. Fan, Semicond. Sci. Technol. $2005,20,44$.

(19) a) M. Pavan, S. Rühle, A. Ginsburg, D. A. Keller, H.-N. Barad, P. M. Sberna, D. Nunes , R. Martins , A. Y. Anderson, A. Zaban, E. Fortunato, Sol. Energy Mater. Sol. Cells 2015 , 132 , 549 ; b) K. E. R. Brown , K.-S. Choi , Chem. Commun. 2006 , 31 , 3311.

(20) C. Malerba , F. Biccari , C. Leonor Azanza Ricardo , M. D’Incau , P. Scardi , A. Mittiga, Sol. Energy Mater. Sol. Cells 2011, 95 , 2848.

(21) C. C. L. McCrory, S. Jung , J. C. Peters, T. F. Jaramillo, J. Am. Chem. Soc. 2013 $, 135,16977$. 
(22) a) F. F. Abdi , L. Han , A. H. Smets , M. Zeman , B. Dam , R. van de Krol , Nat. Commun. 2013 , 4 , 2195 ; b) O. Khaselev , J. A. Turner , Science 1998 , 280 , 425.

(23) J. Luo , J.-H. Im , M. T. Mayer , M. Schreier , M. K. Nazeeruddin , N.-G. Park , S. D. Tilley , H. J. Fan , M. Grätzel , Science 2014 , 345 , 1593 .

(24) N. Pellet , P. Gao , G. Gregori , T.-Y. Yang , M. K. Nazeeruddin , J. Maier , M. Grätzel , Angew. Chem. Int. Ed. 2014 , 53 , 3151.

(25) Z. Chen , T. F. Jaramillo , T. G. Deutsch , A. Kleiman-Shwarsctein , A. J. Forman , N. Gaillard , R. Garland , K. Takanabe , C. Heske , M. Sunkara , E. W. McFarland , K. Domen , E. L. Miller , J. A. Turner , H. N. Dinh , J. Mater. Res. 2010 , 25 , 3 .

(26) a) M. Schreier , L. Curvat , F. Giordano , L. Steier , A. Abate , S. M. Zakeeruddin , J. Luo , M. T. Mayer , M. Grätzel , Nat. Commun. 2015 , 6, 7326 ; b) A. Mei , X. Li , L. Liu , Z. Ku , T. Liu , Y. Rong , M. Xu , M. Hu , J. Chen , Y. Yang , M. Grätzel , H. Han , Science $2014,345,295$.

(27) C. Li , T. Hisatomi , O. Watanabe, M. Nakabayashi , N. Shibata , K. Domen , J.J. Delaunay, Energy Environ. Sci. 2015,8 , 1493 .

(28) J. Jin , K. Walczak , M. R. Singh , C. Karp , N. S. Lewis , C. Xiang , Energy Environ. Sci. $2014,7,3371$.

(29) C. G. Morales-Guio , L. Liardet , M. T. Mayer , S. D. Tilley , M. Grätzel , X. Hu , Angew. Chem. Int. Ed. $2015,54,664$.

(30) A. Paracchino , J. C. Brauer , J. E. Moser , E. Thimsen , M. Grätzel , J. Phys. Chem. C $2012,116,7341$.

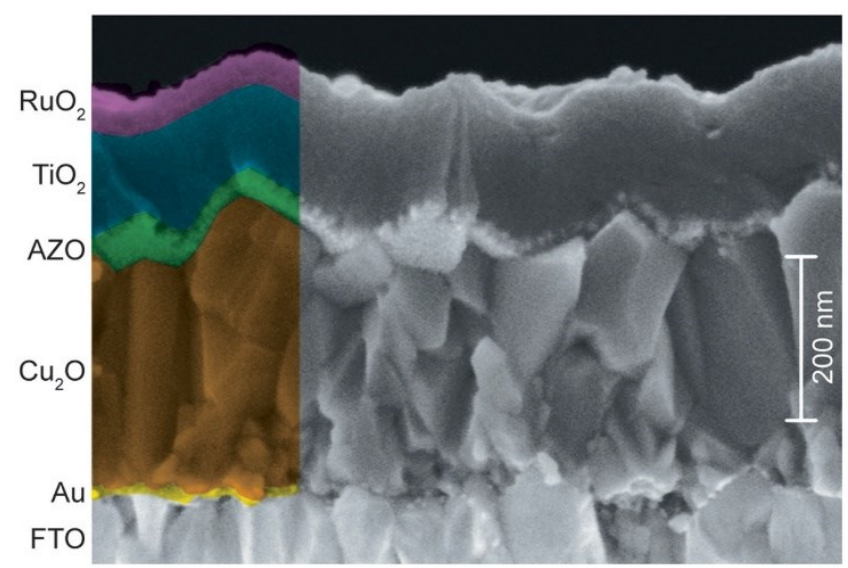

Figure 1. Cross-sectional scanning electron microscopy image of a $\mathrm{Cu} 2 \mathrm{O}$ photocathode device based on an FTO substrate treated with a $3 \mathrm{~nm}$ dose of Au. False-color was added to aid visualization of the layers. 


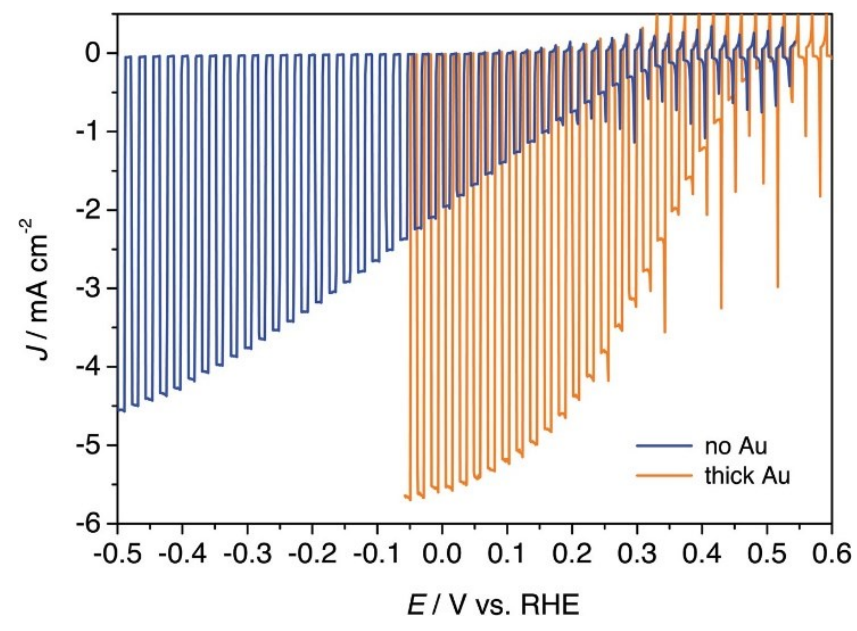

Figure 2. J-E response under chopped illumination for photocathodes synthesized both with and without the presence of a $150 \mathrm{~nm}$ thick Au substrate layer. In the absence of the $\mathrm{Au}$ layer, the performance of the photocathode is severely worsened. Conditions: pH 5 electrolyte, one-sun intensity chopped illumination, $10 \mathrm{mV} \mathrm{s}^{-1}$ scan rate from positive.

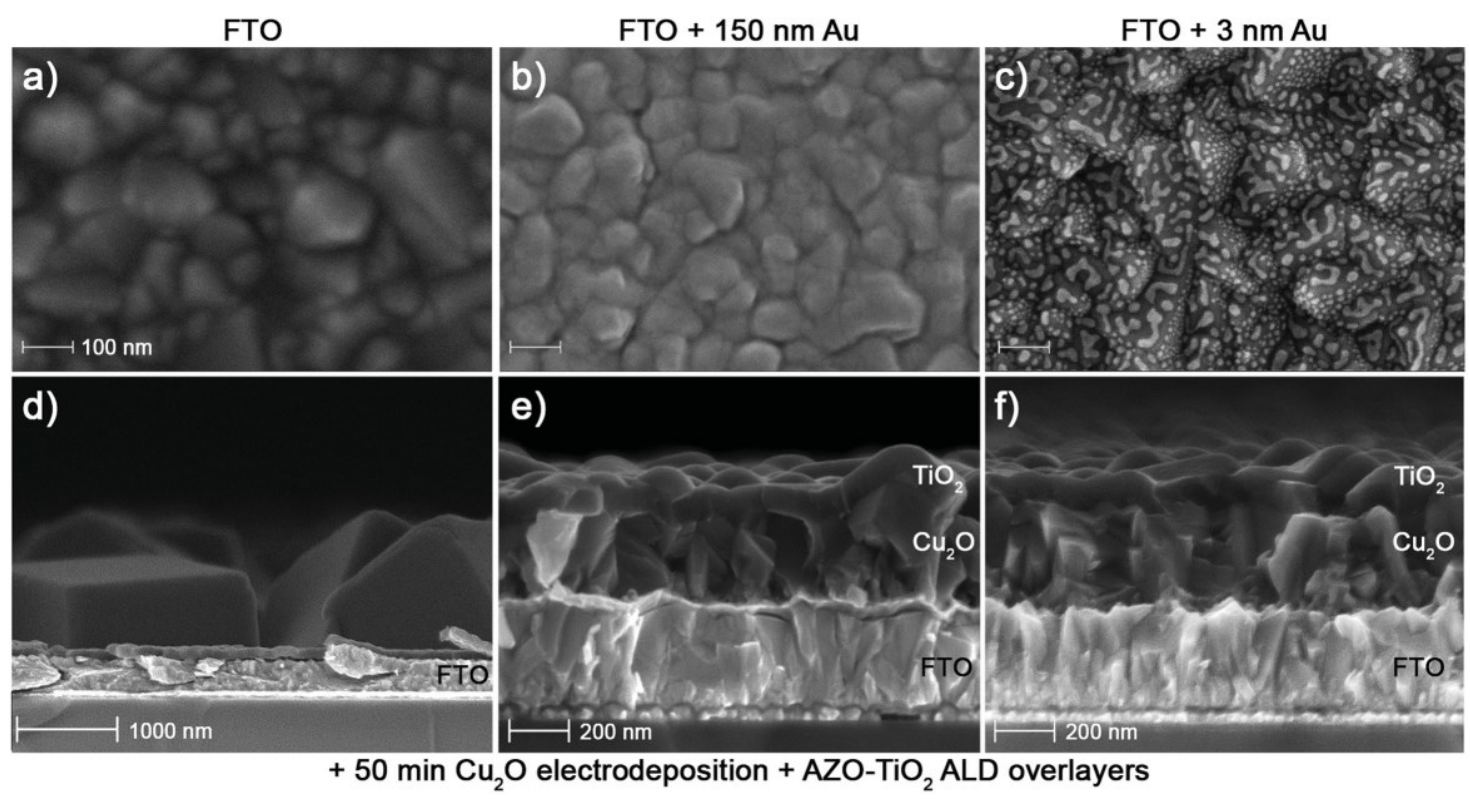

Figure 3. Scanning electron images of different substrates before (top row; top view) and after (bottom row; cross-section view) device fabrication following identical treatments (50 min Cu2O electrodeposition followed by atomic layer deposition of AZO and TiO2 overlayers). The substrates examined were a) bare FTO glass, b) FTO with a $150 \mathrm{~nm}$ thick Au film, and c) FTO with a $3 \mathrm{~nm}$ dose of Au (scale bars: $100 \mathrm{~nm}$ ). On bare FTO, the Cu2O nucleates and grows into large, d) distinct crystalline particles, whereas on both e) $150 \mathrm{~nm}$ and f) $3 \mathrm{~nm}$ Au-treated substrates the $\mathrm{Cu} 2 \mathrm{O}$ growth is uniform, dense, and continuous. 

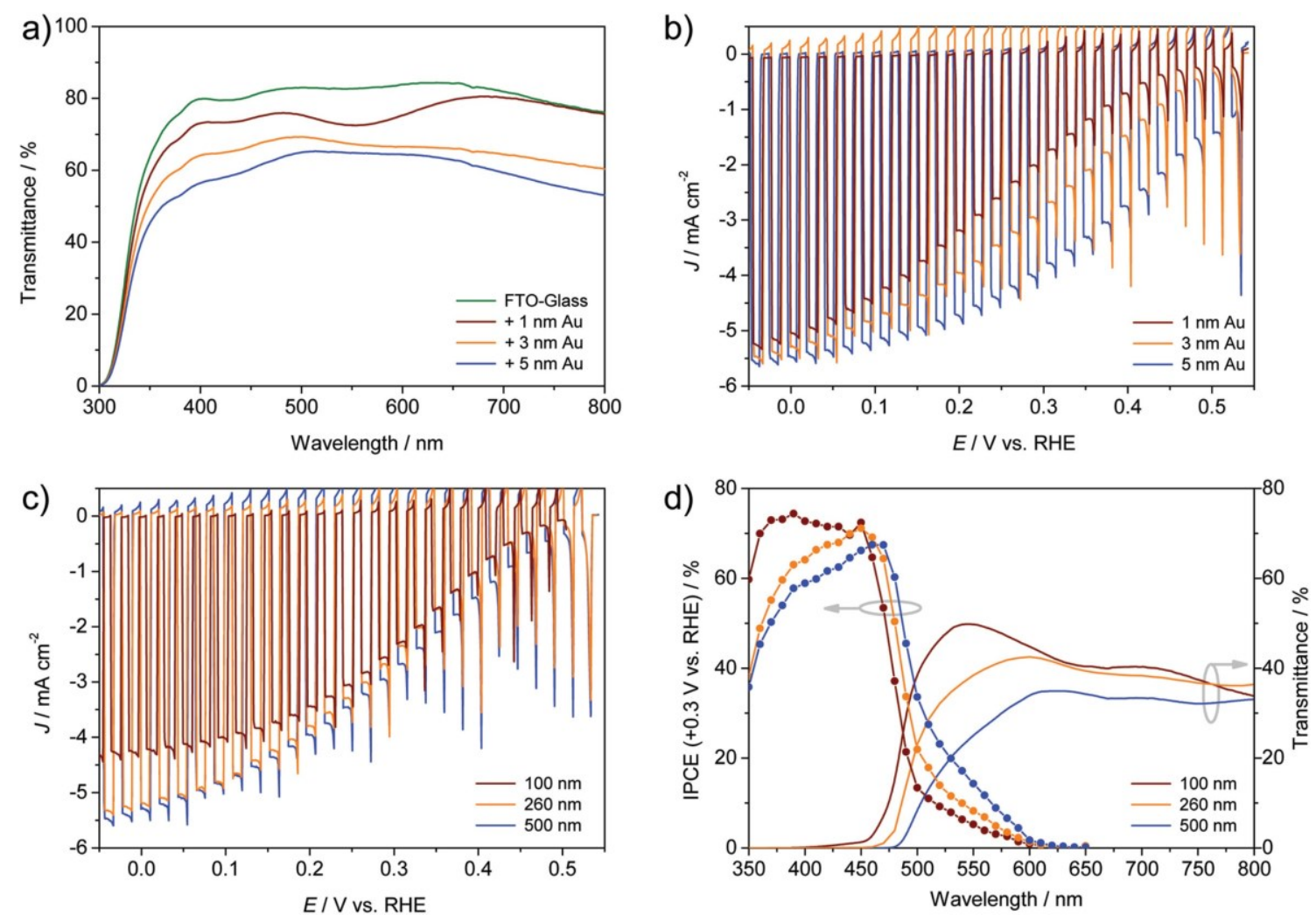

Figure 4. Optical and photoelectrochemical effects of Au and Cu2O thickness variation. a) Transmittance spectra of FTO-glass substrates with the addition of various doses of sputtered Au. b) J-E responses of photocathodes based on $105 \mathrm{~min} \mathrm{Cu}_{2} \mathrm{O}$ electrodepositions onto substrates of various Au treatments, tested in $\mathrm{pH} 5$ electrolyte under 1-sun intensity chopped illumination, with a $10 \mathrm{mV} \mathrm{s}^{-1}$ scan rate from positive. c) J$E$ responses and d) IPCE and transmittance spectra for devices of varied Cu2O thickness formed onto $3 \mathrm{~nm}$ Au-treated substrates. The devices are labeled by approximate Cu2O thickness. The transmittance spectra were obtained on samples in air. The IPCE responses were measured while biased at $+0.3 \mathrm{~V}$ vs. RHE. All photocathodes in $(b-d)$ were tested following 15.0 min of RuO2 catalyst deposition on their surfaces. 


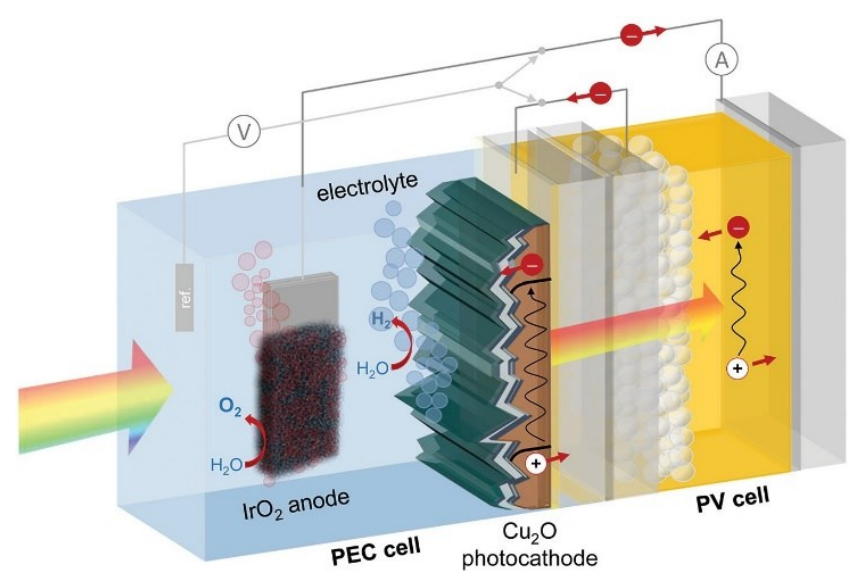

Figure 5. Schematic of the Cu2O-perovskite-IrO2 tandem cell during operation. An ammeter $(A)$ is employed to monitor the short-circuit current flowing through the unbiased tandem device, while a voltmeter $(\mathrm{V})$ is used to periodically measure the potentials of the anode and cathode contacts against a reference electrode in the solution.
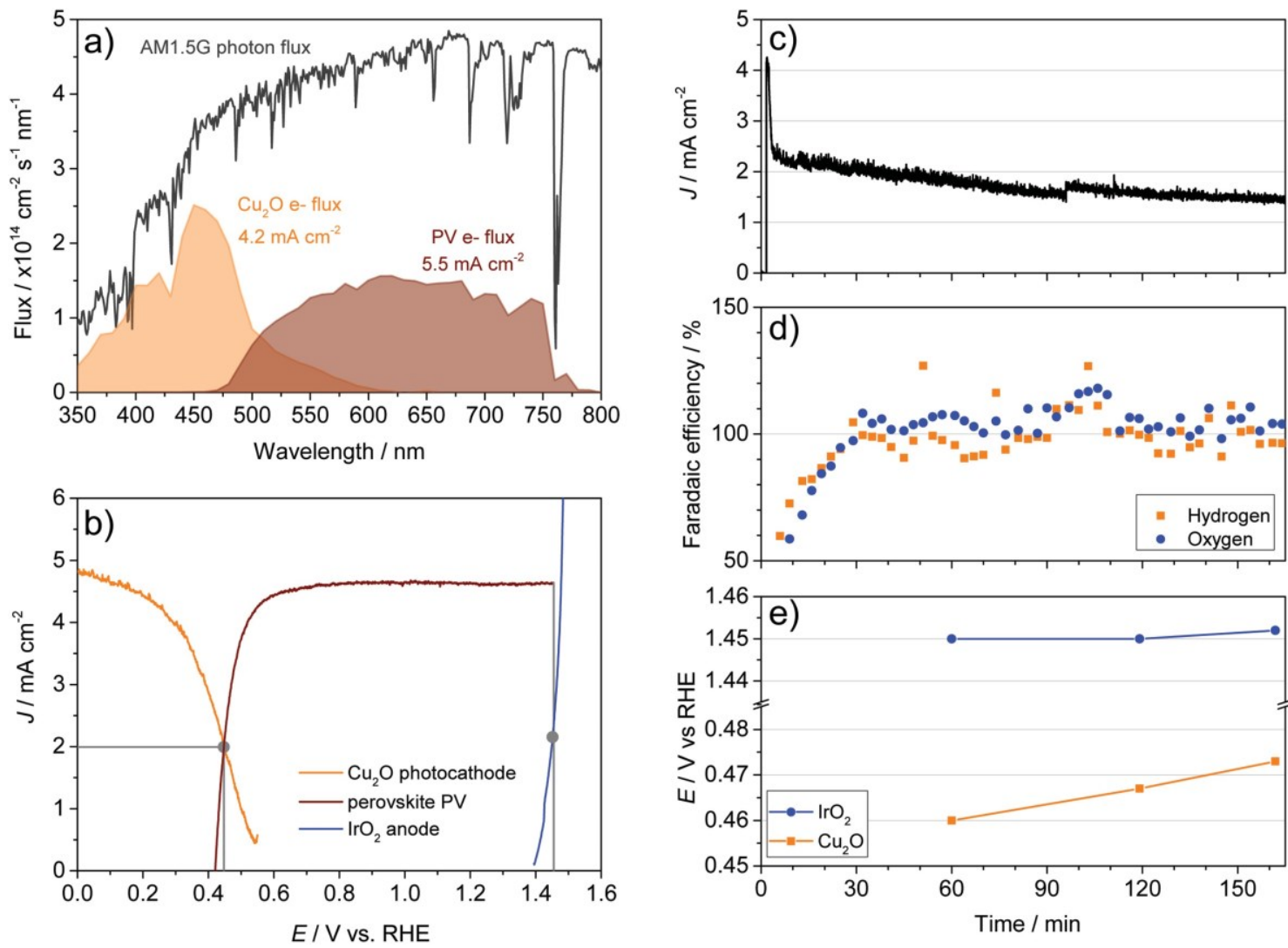

Figure 6. PEC-PV tandem assembly and operation. a) Plot of the spectral flux of photons in the AM1.5G spectrum, and the expected electron current flux of photocathode and PV obtained from multiplication of their respective IPCE responses by the photon flux (note that for IPCE acquisition, the photocathode was biased at $+0.3 \mathrm{~V}$ vs. RHE and the PV was measured at short circuit). Integration yields the expected current densities labeled for each component. b) J-E plots of the photocathode and anode components with overlaid J- 
$V$ response of the photovoltaic cell. The photocathode configuration was $3 \mathrm{~nm} \mathrm{Au}+260$ $\mathrm{nm} \mathrm{Cu} 2 \mathrm{O}+\mathrm{ALD}$ overlayers +20 min electrodeposited $\mathrm{RuO} 2$ surface catalyst. The position of the photovoltaic curve was defined by actual potential measurements at the photovoltaic electrode contacts after 60 min of tandem operation, as indicated by gray markers. c) Photocurrent density, d) Faradaic efficiency from in-linegas measurements, and e) potential measurements during operation of the complete assembled tandem in a sealed, stirred cell under continuous flow of He carrier gas, with a photocathode and photovoltaic illuminated area of $0.057 \mathrm{~cm}^{2}$. Approximately $30 \mathrm{~min}$ were required for the produced gases to reach equilibrium in the cell. 